\title{
University for children: the magic of light
}

\section{Dan Curticapean}

Dan Curticapean, "University for children: the magic of light," Proc. SPIE 9666, 11th Education and Training in Optics and Photonics Conference, 966604 (5 June 2009); doi: 10.1117/12.2207932

Event: Eleventh International Topical Meeting on Education and Training in Optics and Photonics, 2009, St. Asaph, United Kingdom 


\title{
University for Children - The Magic of Light
}

\author{
Dan Curticapean ${ }^{1}$ \\ ${ }^{1}$ University of Applied Sciences Offenburg, Badstr. 24, 77652 Offenburg, Germany
}

\begin{abstract}
The University for Children is a very successful event aiming to spark children's interest in science, in this particular lecture in Optics and Photonics. It is from brain research that we know about the significant dependence of successful learning on the fun factor. Researchers in this field have shown that knowledge acquired with fun is stored for a longer time in the long-term memory and can be used both more efficiently and more creatively [1], [2]. Such an opportunity to inspire the young generation for science must not be wasted. The world of Photonics and Optics provides us with a nearly inexhaustible source of opportunities of this kind.
\end{abstract}

Keywords: 000.2060 Education, Education in Optics and Photonics

\section{INTRODUCTION}

Attracted by the child-friendly logo (Fig. 1) and the motivation to discover Optics and Photonics on a scientific level, more than 170 children from both sides of the Rhine (Germany and France) gathered in our University of Applied Science to be enchanted by the "Magic of Light".

To ensure the success of events of this kind and to gain the children's acceptance, it is highly recommended to use impressive experiments and to combine these with slightly less spectacular experiments in between. Experiences like these are engraved into the children's memories, yielding a positive learning effect. Once the children understand the basic concepts and relations - the fun factor emerges and first success comes

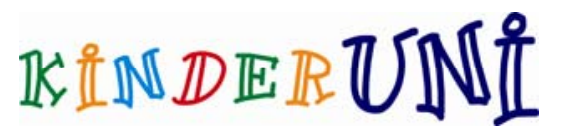

Figure 1: Logo University for Children (C) University of Applied Sciences Offenburg up [3].

The Children's University - having already become tradition at the University of Applied Sciences in Offenburg - was held eight times by now (it is scheduled semiyearly, typically around July and November) by professors from our university. Topics covered by this presentation that is aimed to motivate children for science range from Physics over Chemistry to Biochemistry with a high number of interesting and inspiring experiments. In the last edition of Children's University, I was invited to give a lecture entitled "The Magic of Light" covering the basics of optics to future researchers of age 8-12 in a motivating and child-friendly way. Myself being enthusiastic about the last visit to Frontiers in Optics in Rochester / New York where I met Charles H. Townes [4], John C. Mather, Steven Chu, Emil Wolf and many other celebrities in the field of optics, I was determined to spread this enthusiasm to the children attending the lecture.

\section{PRELIMINARY DIDACTICAL PREPARATIONS FOR THE LECTURE}

Among the most difficult aspects that were considered during the preparations preceding this lecture, the age group of the children - between 8 and 12 years - stands out particularly, since the children's previous knowledge in mathematics and physics cannot be assumed. This imposes a problem since this means in particular that the children are unfamiliar

${ }^{1}$ dan.curticapean@fh-offenburg.de; phone 0049781205 0; fax 0049781205111

Eleventh International Topical Meeting on Education and Training in Optics and

Photonics, edited by K. Alan Shore, Deb Kane, Proc. of SPIE Vol. 9666, 966604

(C) 2009 SPIE, OSA, IEEE, ICO · doi: 10.1117/12.2207932 
with the abstract mathematical modeling of complex processes. Certainly one also needs to adapt both the examples chosen and the language used for explanation, however trying not to lose too much information: As previously stated, we aim for an intuitive grasp of complex concepts and processes occurring in Optics. The lecture "The Magic of Light" was composed of the following topics:

- $\quad$ Light as an electromagnetic wave

- $\quad$ Light is energy

- $\quad$ Light has a speed

- $\quad$ Reflection of light

- Refraction of light

- Total internal reflection of light

- Applications of total internal reflection: optical fibers, optical communication, WDMD

- LASER

- $\quad$ Experiments demonstrating the functionality of the LASER

- $\quad$ Applications of the LASER: laser printer, optical data storage (CD, DVD, Blu Ray)

- $\quad$ LASERs in medicine (SPIE poster)

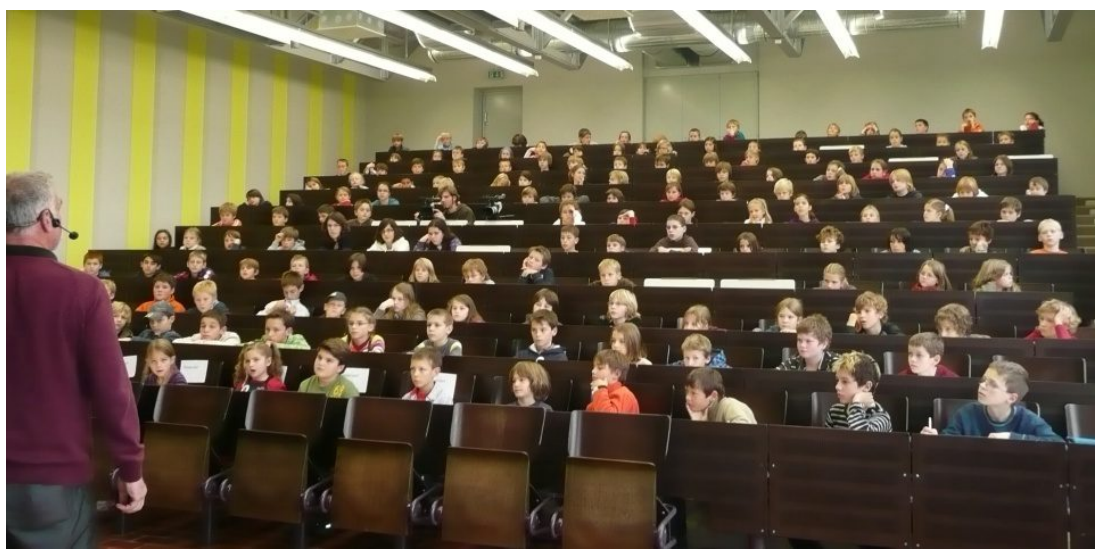

We used experiments that were conducted in front of the lecture hall, graphics, animations, a live-stream and PowerPoint slides. The forms of speech we employed were monologues, dialogues, and in particular the guided conversation. Luckily the children participated actively and also brought in to the lecture an unexpected amount of previous knowledge. Nonetheless they were visibly fascinated by the presented experiments.

Figure 2: Young scientists at a lecture

(C) University of Applied Sciences Offenburg

Lectures of this kind, i.e. lectures incorporating an appreciable amount of experiments, have a very high learning effect even if the experiments are conducted only by the lecturer. Another guarantee of success is the parallel presentation of the experiments and specifically synchronized PowerPoint-slides. This way, the slides operate like instructions for the experiments.

\section{LEARNING GOALS}

To guarantee for the success of the lecture, a correct and precise definition of the learning goals [5] that should be achieved is necessary. Once more, we have to stress the importance of the proper adaptation of the lecture to the listeners' age group of 8-12 years.

The most important learning goal we set up for the lecture was to convey fascination for science (physics in general and optics in particular) and technology to the young audience, since the curiosity and thirst for knowledge of children in this age group is enormous. We point out that the knowledge children in this age achieve with fun is knowledge they can use for their whole life - furthermore, knowledge that has been achieved with fun can also be used creatively later on. This presents an outstanding premise for the potential scientists of tomorrow.

Considering the taxonomy of learning goals proposed by Bloom [6] - [11], we can claim that the learning goals we imposed on the lecture reached level K4: 
- $\quad$ Knowledge (K1): Precise (if not literal) reproduction of information

- $\quad$ Understanding (K2): Ability of applying sense-preserving transformations to knowledge, ability of paraphrasing knowledge in own words and finding examples;

- Application (K3): Ability of applying abstractions, rules, methods, algorithms etc. in concrete situations;

- Analysis (K4): Ability of decomposing ideas and problem settings into its elements and comparing problems, spotting differences;

- $\quad$ Synthesis (K5): Composition of individual elements to a whole;

- Evaluation (K6)

The most important goal of this lecture is to spread enthusiasm for physics and especially for optics to the children. We were aiming at an age-adapted understanding of fundamental concepts such as reflection and also tried to enable the children to reproduce the ideas of refraction and total internal reflection. Furthermore we presented interesting applications of optics such as the optical fiber, the laser - and in turn their applications.

\section{FIGURES, GRAPHICS, ANIMATIONS AND LIVE-BROADCAST}

When striving for a sensible variety of learning media, it is necessary to reach all channels of information flow. However, one must pay attention not to overdose the information input: when overwhelming the audience, it is rather unlikely that much information reaches the intended recipients.

Pictures tell more than thousand words: By the help of suitable figures and posters that were partly provided by the SPIE and OSA, the children were exposed to new views of the world. Combining these figures with animations, one can achieve even more of the learning goals previously described: Animations convey functional interdependencies better than static images. The young audience was obviously fascinated by the images and animations. Quite often we noticed during the lecture that precise questions concerning further applications and relationships to other areas were asked.

\subsection{Graphics}

The usage of figures is of great importance for the success of the lecture. We should not forget that "a picture tells more than thousand words". The self-made images were complemented by images excerpted from learned journals such as Nature and the German magazine "Der Spiegel". The OSA [12] and SPIE [13] also offered a multitude of graphical learning material that was used successfully. For describing semiconductor lasers, the SPIE poster reproduced in Fig. 19 was used, and for presenting the applications of lasers in medicine, we used the SPIE poster in Fig. 20. Furthermore, we used the poster series "Optical Phenomena" by the OSA outside the lecture hall, so that the children were able to contemplate the "Beauty of Optics" before the lecture started.

\subsection{Animations}

The animations were introduced in order to polarize the interest of the young audience. Since children usually like cartoon animations, we assumed a natural affinity for scientific animations. We used animations to demonstrate the functionality of optic fibers and the WDMD. A good animation has to be self-explanatory, should impress and should also be memorable since we want the children to remember the information conveyed by the animation later on in order to use it creatively. If a picture tells more than thousand words, an animation can tell more than thousand pictures [3]. Some animations have been prepared in PowerPoint and accompanied the conducted experiments like instructions.

\subsection{Film Sequences}

The film sequences were used in order to facilitate the understanding of complex processes and applications. In addition, they could be used as a change of pace and last but not least provided for the lecturer's recreation. Film sequences have to be chosen carefully with respect to the topic covered and should not span a too large time frame. For a seamless transi- 
tion from lecture to sequence, we embedded the sequences into the PowerPoint presentation. The video material we chose originated from documentary movies, OSA movies, self-created movies and even two on-the-fly recordings captured during the lecture. In total, we used 8 sequences with a total length of about 11 minutes.

1. Experiment with fire department, Fig. 3 and Fig. 6

2. Optical fiber

3. Production of fibers and functionality of DWDM

4. Functionality of a laser printer

5. Functionality of CD- / DVD-ROM

6. Functionality of a laser, analogy with mouse traps

7. Functionality of a laser, analogy with mouse traps, Fig. 14 - Fig. 15

8. Apollo, Earth-Moon distance measurements
$275 \mathrm{~s}$
$60 \mathrm{~s}$
$89 \mathrm{~s}$
$46 \mathrm{~s}$
$83 \mathrm{~s}$
$76 \mathrm{~s}$
$16 \mathrm{~s}$
Live broadcast
Documentary movie
Documentary movie
Documentary movie, OSA
Documentary movie, OSA
Live broadcast
Self recorded footage
26 s Documentary movie, OSA

\subsection{Live Broadcasting}

The live broadcasting was integrated into the lecture in order to make the previously described outdoor experiment possible. Furthermore, the young audience was able to observe the experiment from two different angles thanks to a splitscreen installation. The success of the experiment could not have been guaranteed without the usage of this split-screen. Furthermore, we established a bidirectional audio connection with the lecture hall. This enabled us to react to the children's wishes and repeat the experiment three times in total.

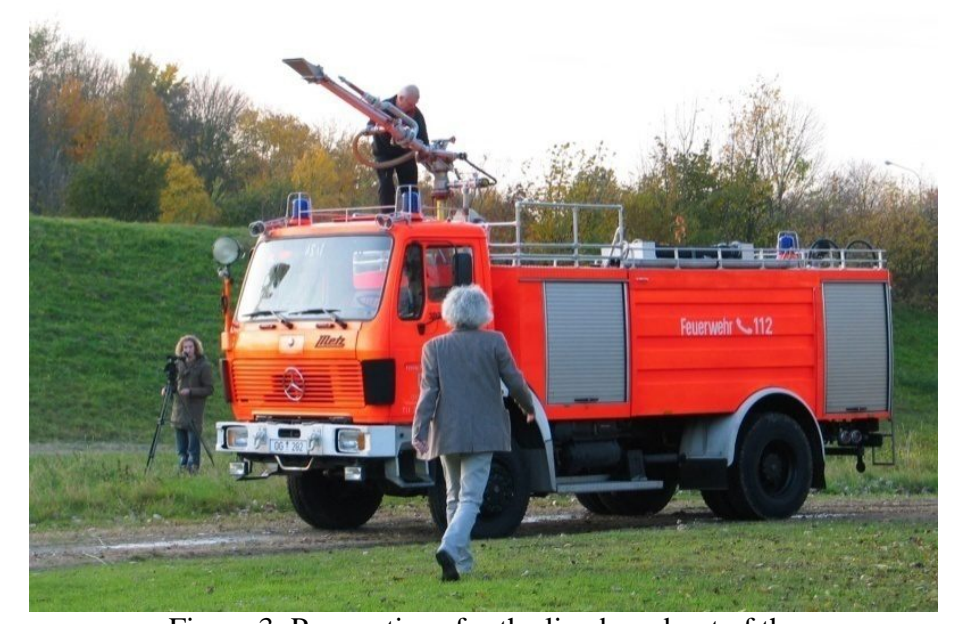

Figure 3: Preparations for the live broadcast of the experiment involving the fire department

\section{THE PHILOSOPHY OF OPTICS FORMULATED CLEARLY IN WELL- UNDERSTANDABLE EXPERIMENTS}

In this part we want to stress some experiments and applications that should yield a visual understanding of optics.

\subsection{The nature of light: Light is an electromagnetic wave}

Figure 4 shows a part of the slide we showed to the children when teaching them that light is an electromagnetic wave and that especially light is composed of the colors one can observe in a rainbow. While showing this slide, a white light beam was decomposed into the color spectrum using a prism at the optical panel. The picture under the caption "experiment", seen at the right side of the slide, depicts the outcome of the experiment - this is exactly what the children were able to observe. Many among them already knew that white light is composed of the rainbow colors.

\subsection{Light is Energy}

It surely is not easy to communicate to young listeners that light means energy - but one can visualize it efficiently by means of a simple yet impressive experiment. This experiment included a Tesla transformer, a so-called plasma lamp. The children were impressed by the effects of the plasma lamp and perceived that its discharges were influenced by hand movements. All these changes were induced by the change of the electromagnetic field surrounding the plasma lamp (Tesla coil). A part of this electric energy was then transformed into light by means of a neon tube. (Fig. 5) 

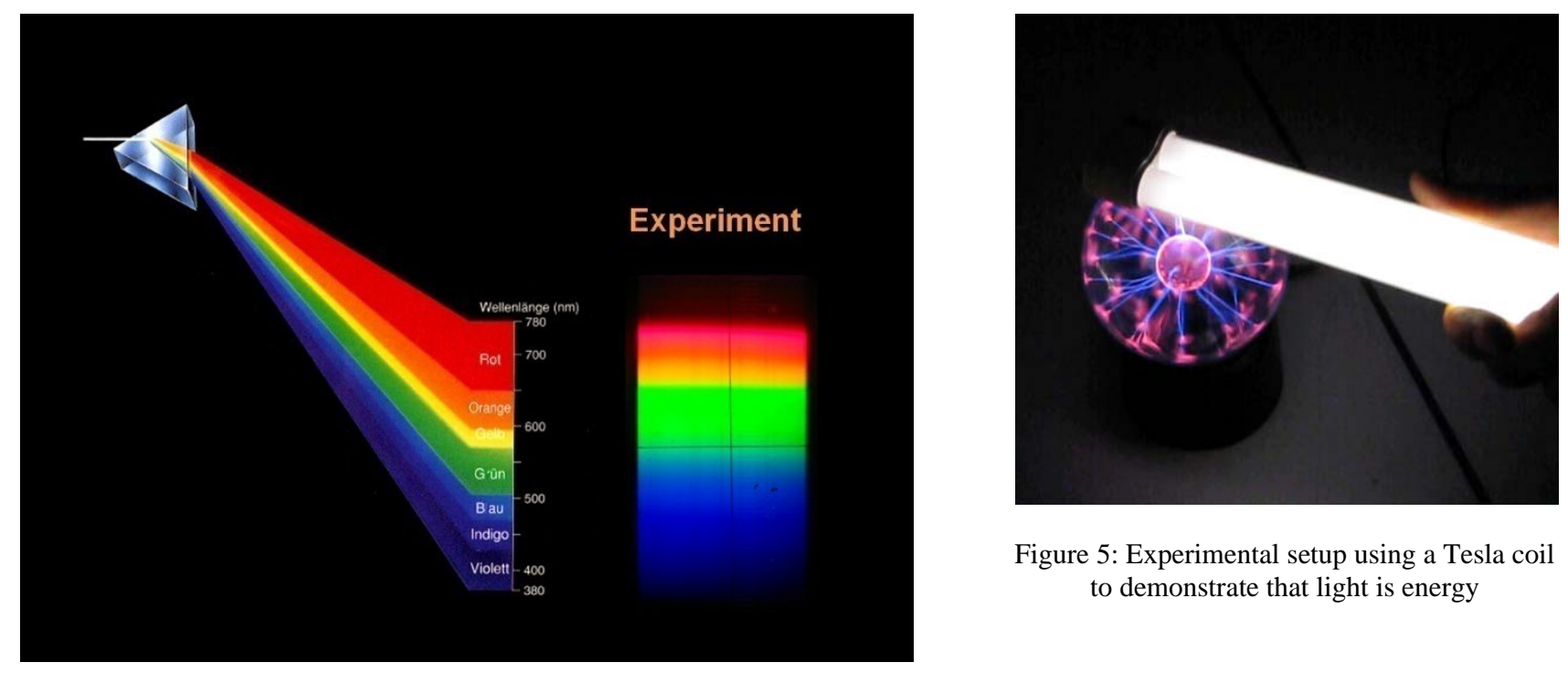

Figure 5: Experimental setup using a Tesla coil to demonstrate that light is energy

Figure 4: Experiment - Light is an electromagnetic wave

\subsection{Light has a speed}

As is well-known, we look into the past when contemplating the starry sky. In a dialogue we conducted with the children, we found out that some among them already knew that light has a speed amounting to about 300.000 kilometers per second. Some of them even explained this speed as "fast enough to travel eight times around earth in one second”. Given this previous knowledge, we could explain together with the children why we see the past images of stars in the sky: Light needs a certain time to cover the distance to Earth. We wanted to impart this knowledge to all participants and in a guided dialogue we found out that we can compare traveling light with a water beam. It was very interesting to find out who would be best suited for an experiment involving water rays. It didn't take long for their answer to occur: "Of course! The fire department!” Naturally, the children were highly

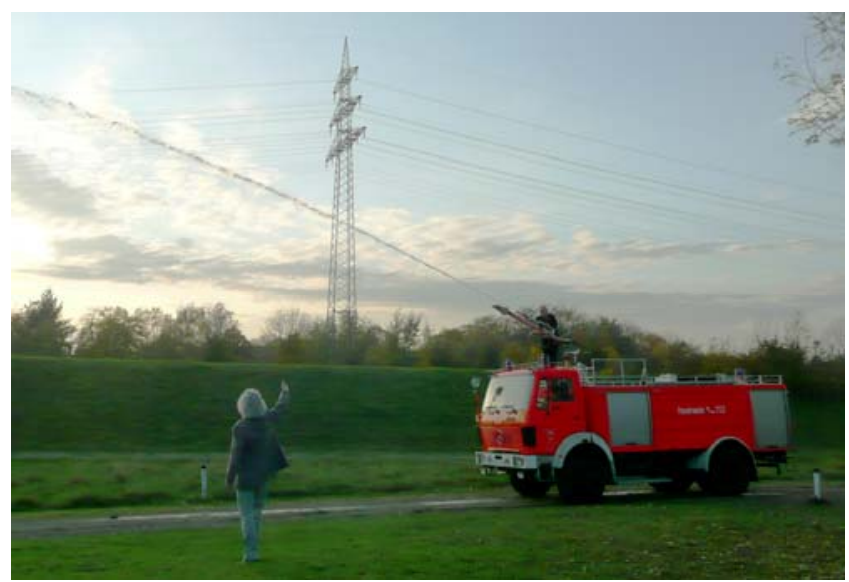

Figure 6: Performed experiment using the analogy between light rays and water rays surprised when a fire engine stood in front of our door, ready for our experiment (Fig. 6). This didactic measure was obviously intended and created a great amazement. To guarantee the success of learning, the experiment was broadcasted into the lecture hall by means of a video transmission. For a better visualization and understanding, we recorded the experiment from two different angles: frontal and perpendicular to the water jet. This experiment caused a big delight, forcing us to repeat it two times and to play the recorded footage. 


\subsection{Reflection, refraction and total internal reflection}

In the first part of the lecture we focused on the foundations of geometric optic. First, we deduced the law of reflection experimentally and helped the children to formulate it in their own manner (Fig. 7).

Since we assumed that a deduction of the law of refraction is not possible for children in the age of 8-12 years, we only presented an example (Fig. 8) and stated that the light ray is subject to a break and that this effect can appear only when light passes the border between two optical media that have different optical densities [14].

When presenting total internal reflection (Fig. 9), we showed that this effect appears only when light passes from an optically dense medium to a medium with lower optical density, that there exists a critical angle for this phenomenon and especially that the angle of incidence equals the exit angle as previously stated for the reflection.

To improve the learning success, the experiments were conducted under accompaniment of a dynamic PowerPoint slide providing more theoretical background.

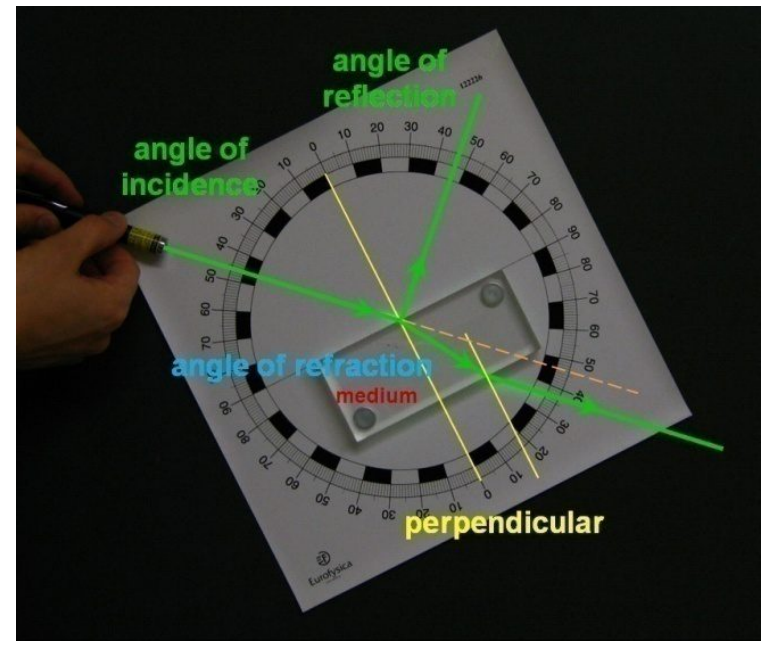

Figure 8: Experiment for explaining refraction

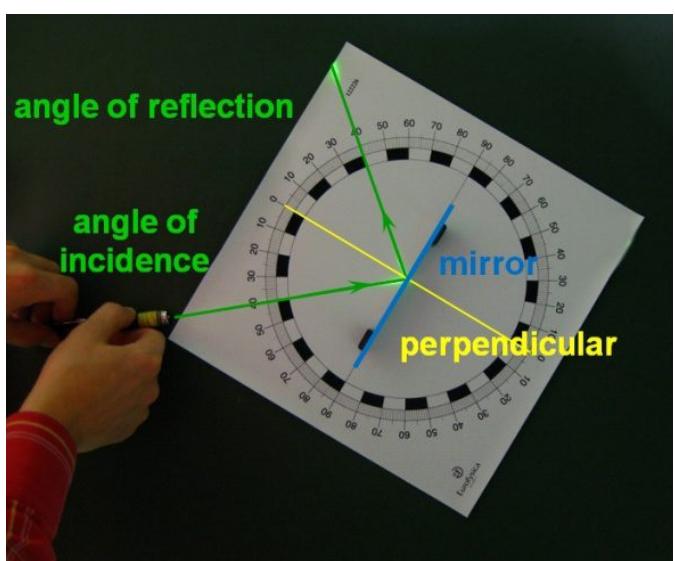

Figure 7: Experiment for explaining reflection

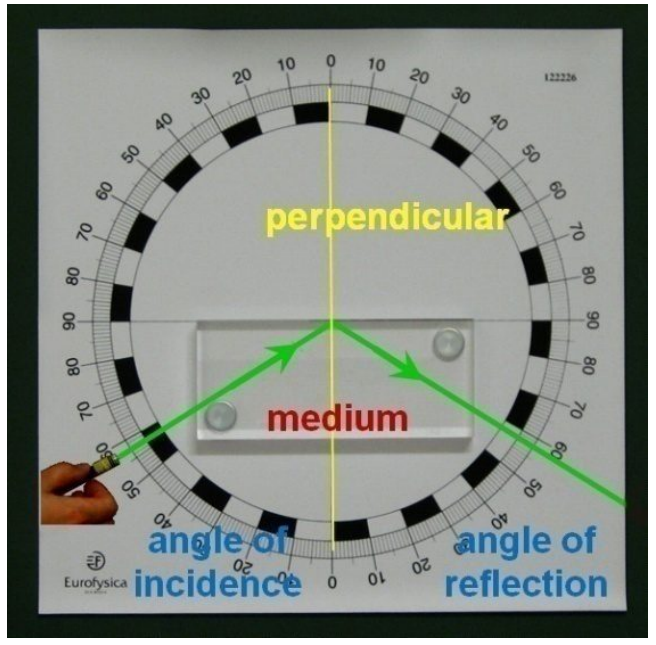

Figure 9: Experiment for explaining total internal reflection

\subsection{Optical fiber and optical communication}

To demonstrate the functionality of an optical fiber, a previous definition of total internal reflection is necessary. To reach this goal, we firstly presented a laser beam that was "trapped" in a water jet - a simple yet quite impressive experiment.

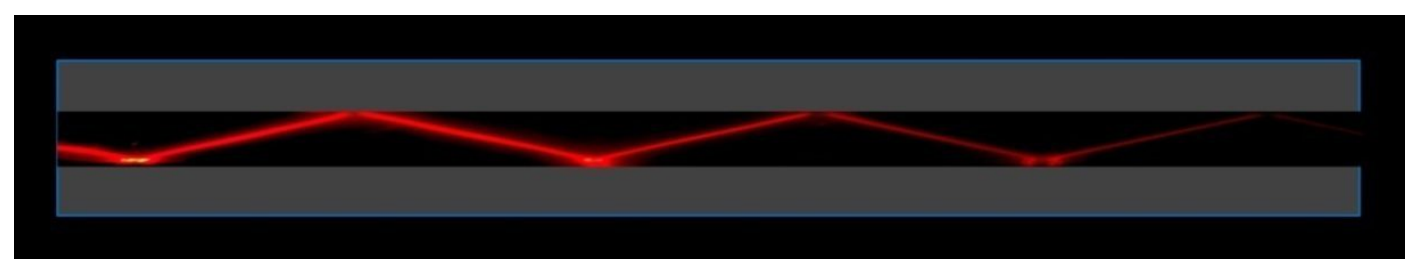

Figure 10: Model of light propagation in an optical fiber 


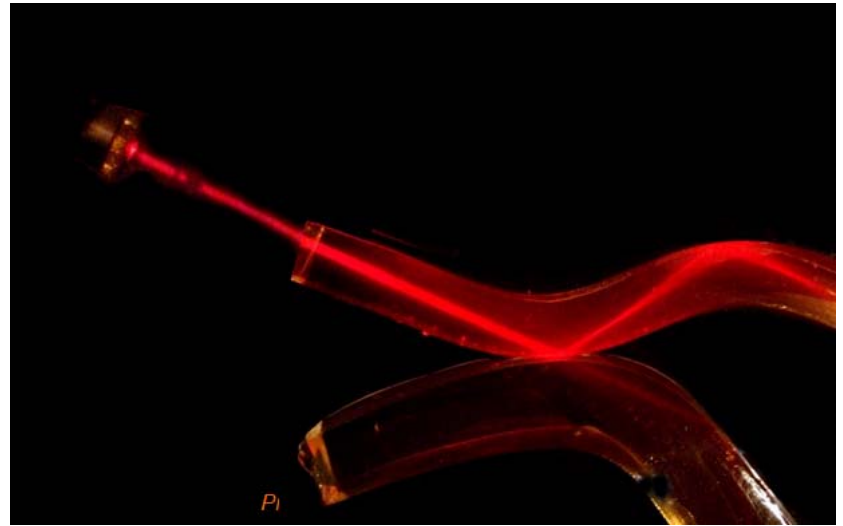

Figure 11: Laser beam in gelatin another model of light propagation in optical fibers
An easy way to describe the propagation of light through an optical fiber is an experimental setup including a laser beam between two parallel mirrors, as seen in Fig. 10. The reflection of the beam at both mirrors represents the total internal reflection between the core and the cladding of the optical fiber [15] - [17].

Another very beautiful experiment that describes the propagation of light in optical fibers very clearly is the "laser beam in gelatin". The advantage of this experiment lies in the fact that it becomes possible to show how light propagates in curved areas and coupled optical fibers (Fig. 11).

The children were able to apply the previously obtained knowledge of total internal reflection and furthermore suggested their own examples and were able to explain the reason why light can propagate through an optical fiber although this

fiber might be bent and wound. Then we proved this using the experiment setup described in Fig. 11.

Equipped with these new insights, the young audience was able to understand the way in which messages are transmitted in optical communications. Since digitally coded information can be represented as a string containing only zeros and ones, the children understood that a "one" can be translated to "light" and a "zero" to "no light". In order to deepen this understanding, we used an animation whose final frame is reproduced in figure 12 . The model optical fiber was equipped with a sender that emitted light pulses and a receiver that registered the pulses. The light pulses propagate from sender to receiver as shown in the animation while the transmitted bits are represented in green.

A further learning effect was achieved when presenting the possibilities of transferring acoustic signals by optical media. The effect reached its maximum when the children found out that the signal transmission is interrupted when the light beam is interrupted e.g. by a hand. An interesting remark concerning this experiment was the question whether it would be dangerous to hold a hand in the laser beam. This proves the achievement of a higher $K$ value in the learning goal hierarchy. The children were amazed when finding out that e.g. in the automotive industry there exist lasers that can cut off a hand instantly. The technology used to pass optical fibers was presented in a movie sequence of about 90 seconds' length taken from a documentary movie. Furthermore, we

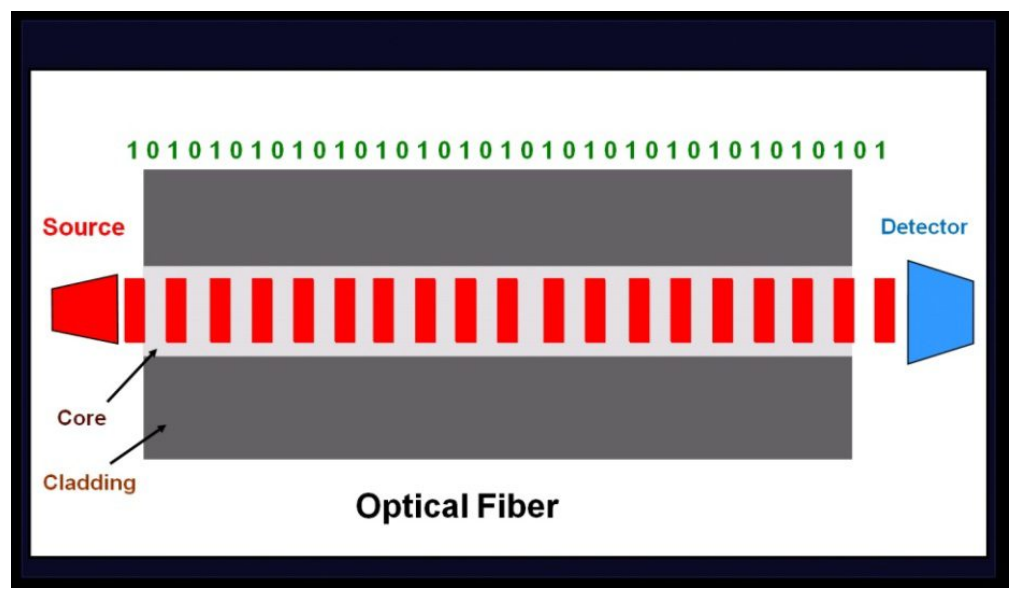

Figure 12: Final still frame of an animation to explain the propagation of light and information through an optical fiber used a movie of about 3 minutes' length to summarize the fabrication of optical fibers. Finally, the enormous amount of data that can be transmitted with an optical fiber (1.5 TB) was emphasized.

Next we presented the Wavelength Division Multiplexing and Demultiplexing WDMD method [15] that decomposes light into its "color components" and enables further use of the single color channels. To reach this goal, the drawing reproduced in figure 13 was used. By means of a suitable animation the children were able to see the way in which the pulses of colored light originating from the individual light sources mix up in the optical fiber and are subsequently de- 
coupled in order to transmit them to the individual receivers. This drawing additionally showed the increase in transmission rates and provided an overview of the optical fiber-based networking in Europe [18].

\subsection{Laser}

One of the most challenging parts of the lecture was to explain the functionality of the laser to the young audience. After explaining the term "laser" as an acronym of "Light Amplification by Stimulated Emission of Radiation”, we included another surprise experiment after long consideration. In this experiment, we modeled the concept of a chain reaction adapted to the nature of light and also described the limits of the experiment to the children.

The experiment consists of about 30-40 mouse traps that have been wound up and on which a table tennis ball was placed. The complete setup was surrounded by a Perspex box, as depicted in Fig. 14. We firstly explained to the children that every mouse trap corresponds to one atom and that the table tennis ball represents a photon emitted by the atom. An additional ball (corresponding to the initial photon) was dropped into the box through an opening. This caused a rapid triggering of the mouse traps that in turn made the balls in the box bounce (Fig. 15). Unfortunately, the analogy here reaches its limits. We explained to the children that in a laser the photons represented by table tennis balls reflect from the two mirrors of the gain medium (in our case represented by the box). One of the two mirrors is slightly transparent and allows photons to pass when they have achieved the necessary intensity by sufficiently many reflections.

Although this experiment is quite beautiful, its success is not very obvious. On the one hand, it might be possible that the children don't understand the analogy and on the other hand, the mouse traps could be triggered by the slightest vibration. The latter happened during the preparations directly preceding the lecture - but thanks to the aptitude of our assistants we were able to reconstruct the setup just in time for the lecture. To minimize the first risk stated we recorded the experiment during the lecture and showed slow motion footage of it while simultaneously explaining the events step by step. We finally once more emphasized the limits of the analogy underlying the experiment.

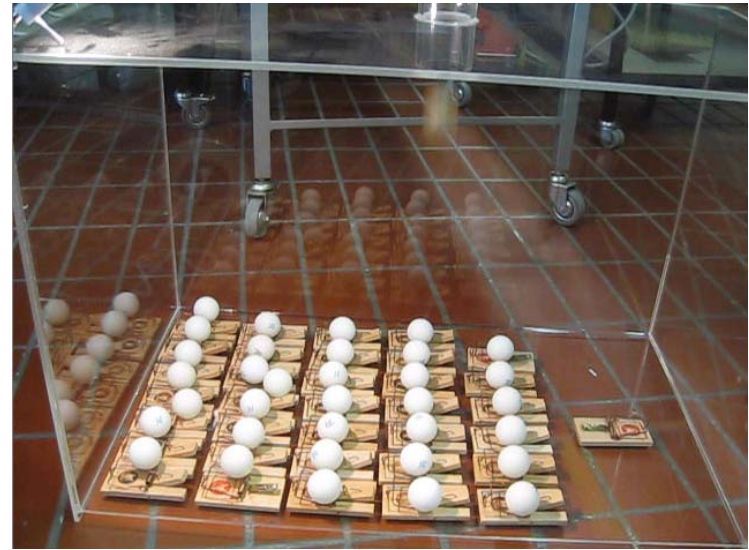

Figure 14: Model explaining the functionality of the laser - before the experiment

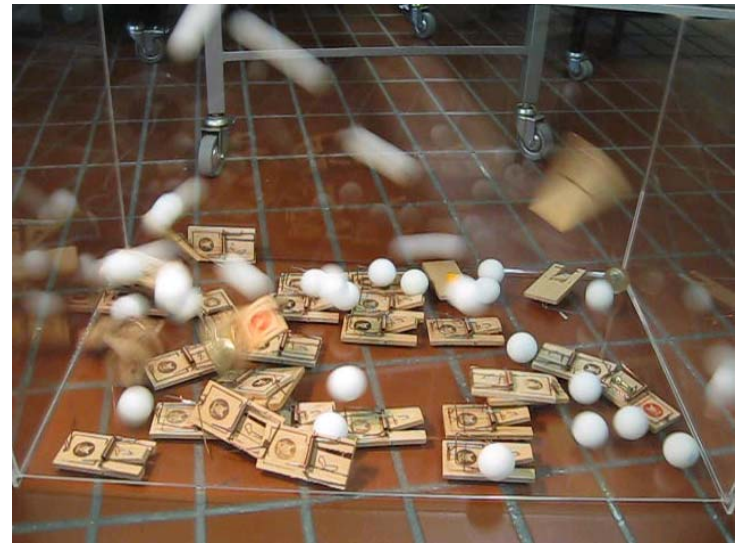

Figure 15: Model explaining the functionality of the laser - during the experiment 


\subsection{Laser Applications}

To show some applications of the laser in everyday life, we first explained the functionality of CD-ROMS, DVD-ROMs and Blu-Ray discs by a movie sequence produced by the OSA [12]. Additionally, the future optical storage media which will be able to store data by the two photon technology were presented.

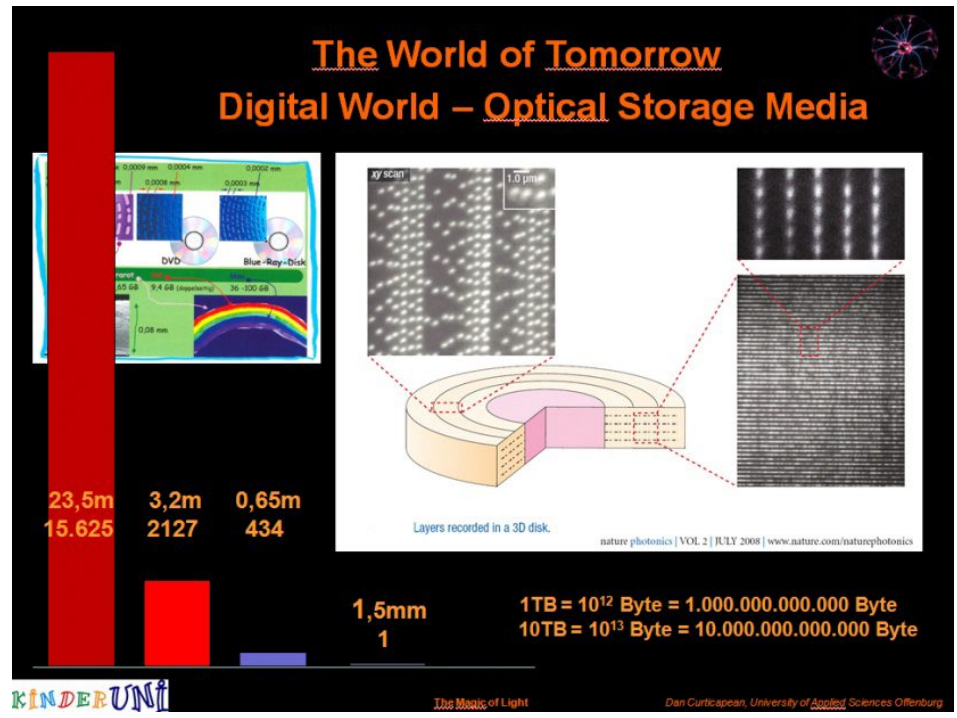

Figure 16: Slide - Laser Application in optical data storage, comparison between CD-ROM, DVD-ROM, Blu Ray and the next generation two photon storage media WORM [19]

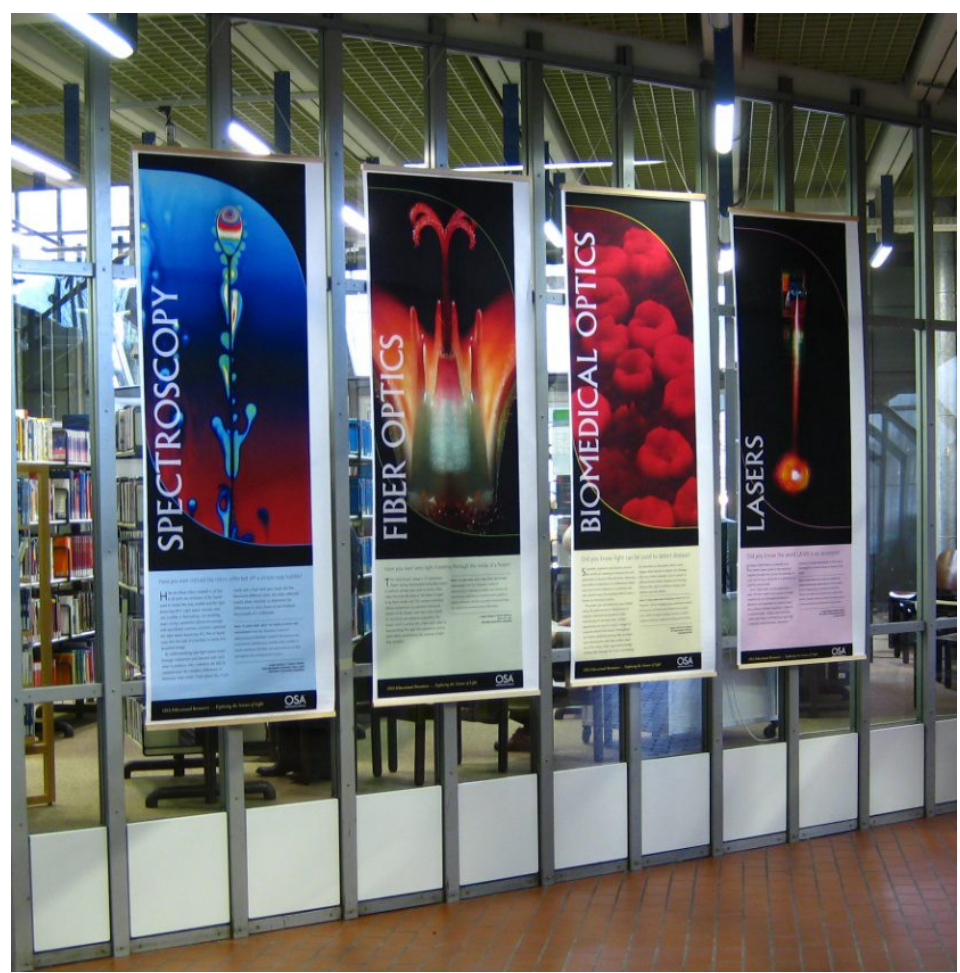

The enormous amount of data that can be captured by these optical storage media was compared to the capacity of today's media. In numbers: A WORM could store the amount of data that would otherwise require 15,600 CD-ROMs, $2100 \mathrm{DVDs}$ or 230 Blu Ray discs. These amounts of media would pile up to $23.5 \mathrm{~m}, 3.2 \mathrm{~m}$ or $65 \mathrm{~cm}$ respectively. Another application we presented was the laser printer, whose functionality was explained by a movie sequence and a dismantled laser printer. The last application we presented was the measurement of distances by means of lasers and the resulting possibility of measuring the distance between Earth and Moon with errors in the dimension of a few centimeters.

A good diversion was provided by the Optical Phenomena Poster Series by the OSA. Impressed by the beautiful pictures of optics, the children's curiosity reached an even higher level.

www.osa.org or

http://www.opticsforkids.org/teachersparents/o utreach/

Www.spie.org

http://spie.org/x31474.xml

Figure 17: OSA's Optical Phenomena Poster Series in our University (exhibited in the corridor). 


\section{OSA AND SPIE EDUCATIONAL MATERIAL}
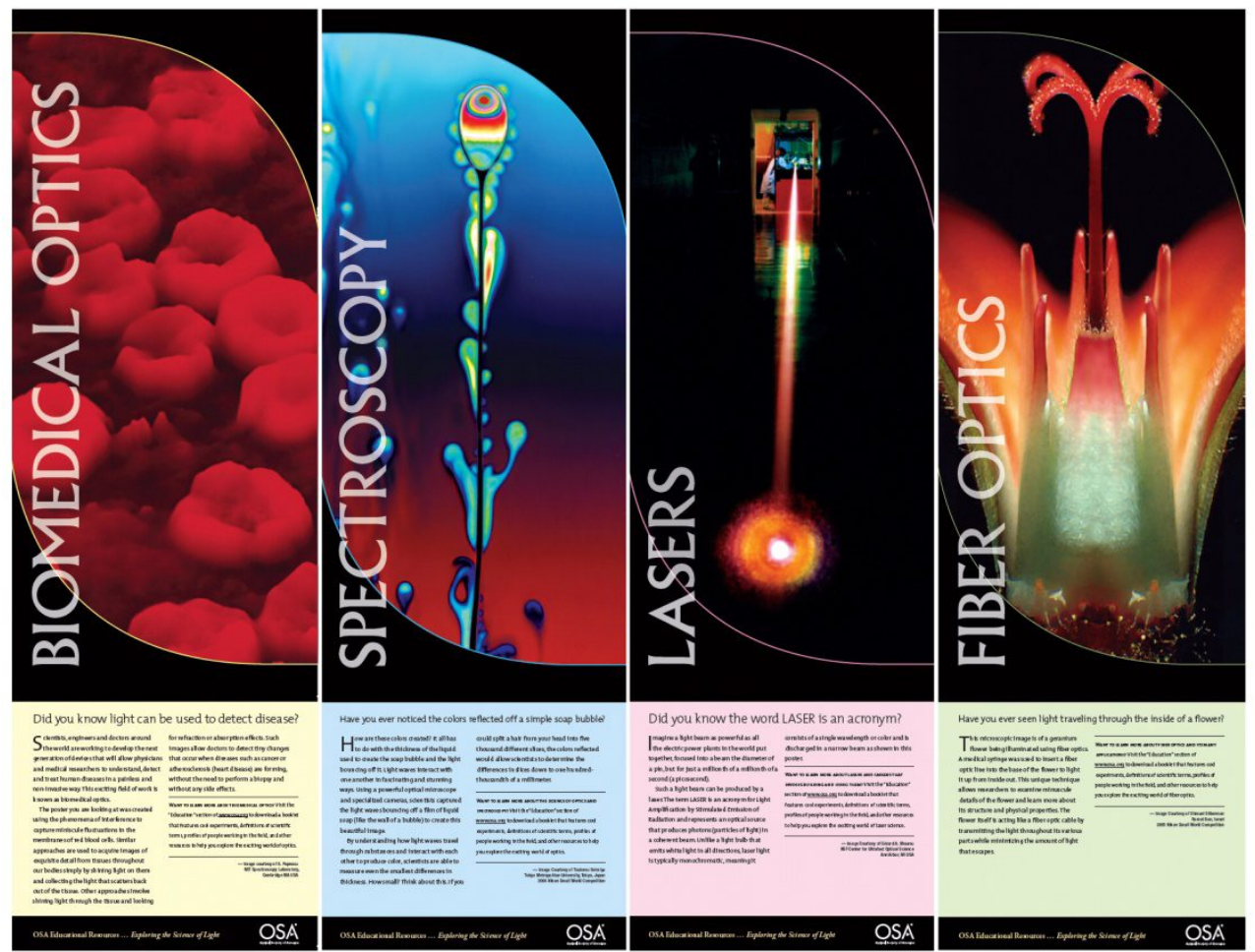

Figure 18: OSA - Optical Phenomena Poster Series [12] (C) OSA

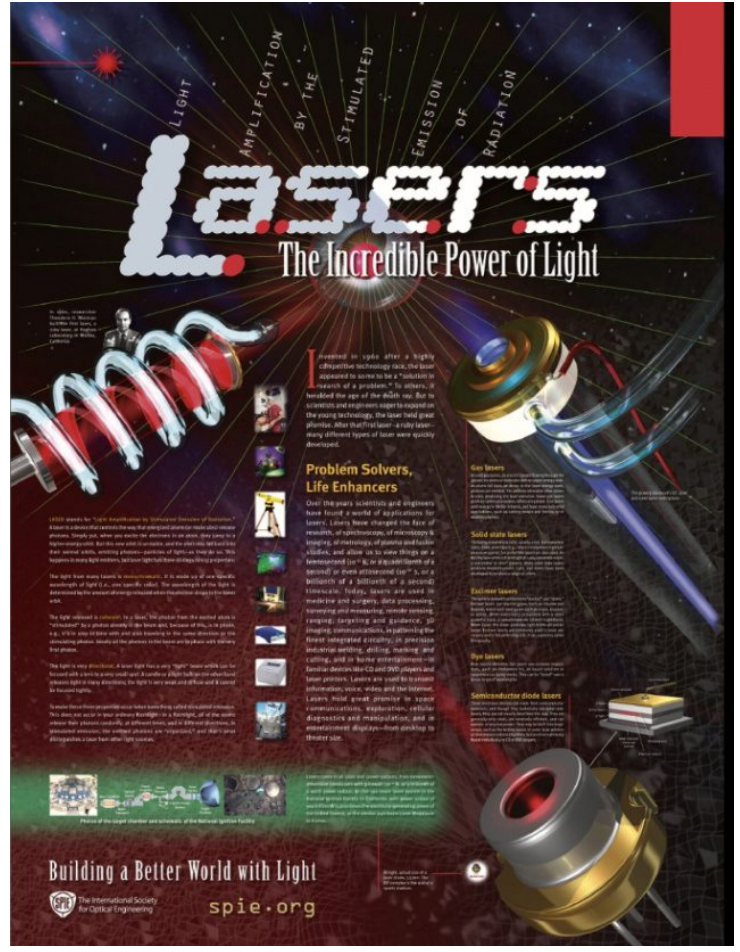

Figure 19: SPIE poster - Semiconductor lasers [13] @ SPIE

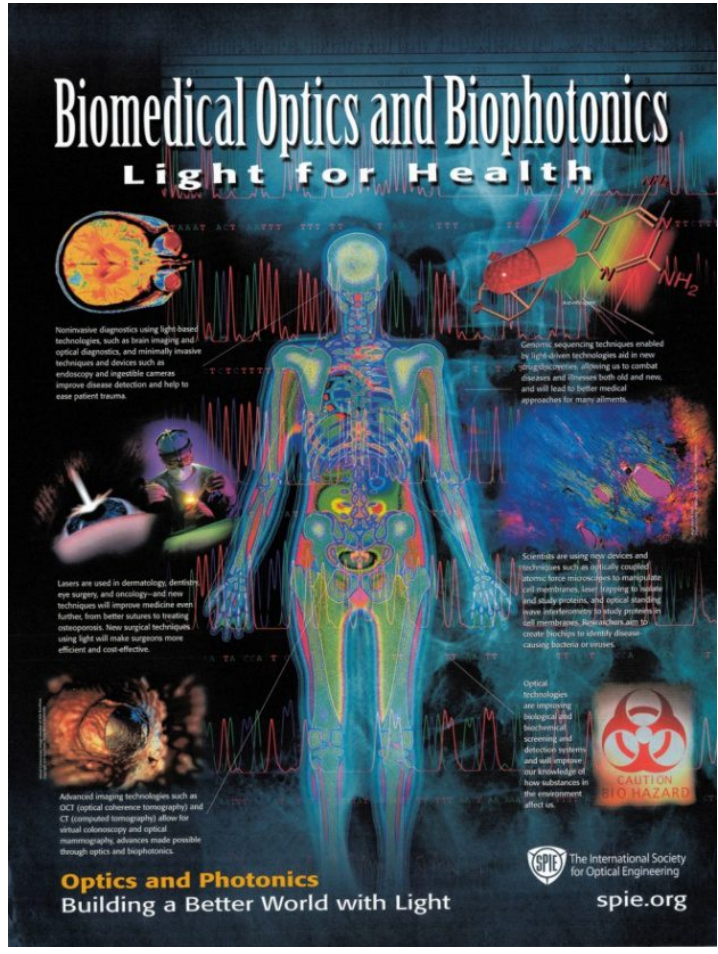

Figure 20: SPIE poster - Applications of lasers in medicine [13] @ SPIE 


\section{CONCLUSION}

As a general conclusion, we can claim that the children had very much fun during the lecture. This was emphasized by repeated applauses and calls for encore. In the lecturer's point of view, the learning goals have been achieved and - in some situations - even exceeded by the children's unexpected collaboration and previous knowledge that they applied successfully. Furthermore, we are quite convinced that the experiments will stay in the children's minds.

Last but not least the children were positively surprised by the events.

Together with colleagues from the Laboratoire des Systemes Photoniques from the University of Strasbourg, we intend to translate the courses to make them available to a French audience.

\section{Acknowledgements}

It is common practice to welcome the participants of the Children's University with a small present. By the kind support of the Thorlabs Company, we were able to offer to each participant a ball pen with an impressive integrated LED illumination. We once more want to thank Dr. Angelika Küng, manager at Thorlabs who ordered the LED ballpens directly from the USA for us.

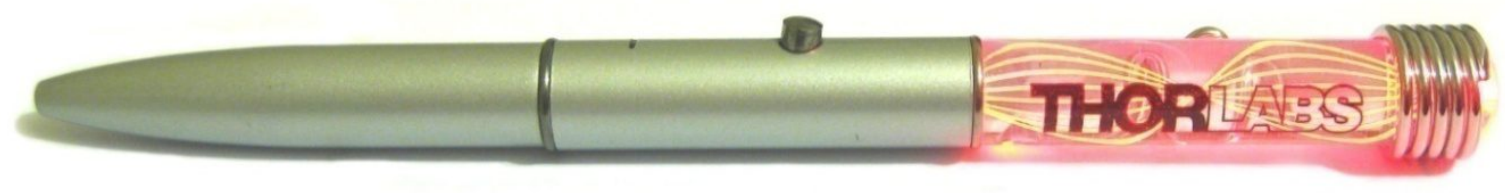

Figure 21: Present for the participants

Thanks also to the OSA and the SPIE for their kind support with the excellent learning aids (posters, movies) published on their web sites. Thanks to Nature and VDE for the provided figures.

We also want to thank the organization team of the E-Day (San Jose/California 2007 and Rochester/New York 2008) in the annual Frontiers in Optics conference that created a platform for many interesting discussions with other people teaching optics.

For their involvement in the lecture "The Magic of Light" we also want to thank the Fire Department Offenburg. Without their help, one substantial experiment could not have been presented so impressively.

\section{REFERENCES}

[1] Manfred Spitzer: Lernen: Gehirnforschung und die Schule des Lebens - Spektrum Akademischer Verlag (2006) ISBN-10: 3827417236

[2] Gerhard Roth, Manfred Spitzer, Ralf Caspary: Lernen und Gehirn: Der Weg zu einer neuen Pädagogik - Verlag: Herder, Freiburg; Auflage: 5., Aufl. (2008) ISBN-10: 3451057638

[3] Dan Curticapean: Die Macht der Animationen im Unterricht der Naturwissenschaften - eine didaktische Betrachtung - Energie der Didaktik - Beiträge zum 7. Tag der Lehre, pag 111 - 114, 2007 ISBN: 978-3-00-022550-5

[4] Charles H. Townes: How the Laser Happened, Adventures of a Scientist - Oxford University Press, Inc. New York, Oxford 1999, ISBN 0-19-512268-2 
[5] Robert F. Mager: Lernziele und Unterricht. Beltz, Weinheim 1994

[6] Benjamin S. Bloom: Taxonomie von Lernzielen im kognitiven Bereich. 4. Auflage. Beltz Verlag, Weinheim und Basel 1972

[7] Max D. Engelhart, Edward J. Furst, Walker H. Hill, Benjamin S. Bloom: Taxonomie von Lernzielen im kognitiven Bereich, Beltz Verlag, Auflage 5. A. 2001, ISBN-10: 3407182961

[8] Lorin W. Anderson, David R. Krathwohl (Hrsg.): A Taxonomy for Learning, Teaching, and Assessing. A Revision of Bloom's Taxonomy of Educational Objectives. Addison-Wesley, New York 2001

[9] D. R. Krathwohl, B. S. Bloom, B. M. Bertram: Taxonomy of Educational Objectives, the Classification of Educational Goals. Handbook II: Affective Domain. David McKay Co. Inc., New York 1973

[10] Krathwohl, D. R./ Bloom, B. S./ B. B. Masia: Taxonomie von Lernzielen im affektiven Bereich. Beltz, Weinheim 1978

[11] Claus Bühler: Zweidimensionale Taxonomie von Lernzielen und Inhalten im kognitiven Bereich 1980

[12] www.osa.org or http://www.opticsforkids.org/teachersparents/outreach/

[13] www.spie.org or http://spie.org/x31474.xml

[14] Max Born, Emil Wolf: Principles of Optics - Cambridge University Press $7^{\text {th }}$ expanded edition, Cambridge 2007

[15] Bahaa E. A. Saleh, Malvin Carl Teich: Fundamentals of Photonics, Second Edition - John Wiley \& Sons, Inc., New Jersey 2007, ISBN: 978-0-471-35832-9

[16] Graham T. Reed, Andrew P. Knights: Silicon Photonics, an Introduction - John Wiley \& Sons, Inc., New Jersey 2004, ISBN 0-470-87034-6

[17] Katsunari Okamoto: Fundamentals of Optical Waveguides - Second Edition, Academic Press, Elsevier Inc. Amsterdam, Boston, Heidelberg, London 2006

[18] *** Buntes Licht im Superkabel - Der Spiegel 24/2002 pag. 188

[19] nature photonics, Vol. 2, No. 7, July 2008, technology focus: Optical data storage, “Two-Photon Technology A new dimension”, pag. 406 - 408; www.nature.com//naturephotonics 